This is a self-archived version of an original article. This version may differ from the original in pagination and typographic details.

Author(s): Lilja, Niina; Piirainen-Marsh, Arja

Title: Connecting the Language Classroom and the Wild : Re-enactments of Language Use Experiences

Year: 2019

Version: Accepted version (Final draft)

Copyright: (C) Oxford University Press 2018

Rights: In Copyright

Rights url: http://rightsstatements.org/page/InC/1.0/?language=en

Please cite the original version:

Lilja, N., \& Piirainen-Marsh, A. (2019). Connecting the Language Classroom and the Wild : Reenactments of Language Use Experiences. Applied Linguistics, 40(4), 594-623.

https://doi.org/10.1093/applin/amx045 


\section{Connecting the language classroom and the wild: Reenactments of language use experiences}

\section{Introduction}

The socially situated nature of learning has been explored from multiple theoretical perspectives in applied linguistics (see e.g. Lantolf \& Thorne 2006, Norton 2000, Kramsch 2000, Kasper \& Wagner 2011). Among these, conversation analytic research on second language use and development (CA-SLA) has shown that language learning involves active, occasioned, and embodied participation in social activities and is intrinsically related to the methods of achieving, maintaining and restoring intersubjectivity (see e.g. Gardner \& Wagner 2004, Lee 2010, Hall, Hellermann \& Pekarek Doehler 2011, Eskildsen \& Wagner 2013, 2015; Lilja 2014). While such understanding of learning is already well established, it has only recently been adapted to second language teaching (see BarrajaRohan 2011, Clark \& Lindemalm 2011, Thorne 2013). This study builds on recent initiatives for supporting learning in-the-wild (see Wagner 2015) and investigates how reenactments of language use experiences in everyday social encounters engender learning activity in the classroom.

Using multimodal conversation analysis, this paper analyses language learning as an in situ process shaped by the participants' situated practices during a teacher-assigned, experientially based pedagogical task that was designed to bridge the gap between the language classroom and the learners' life-worlds. The task involved a simple three-part pedagogical structure, where learners first prepared for interactions in real life service encounters, then participated in the encounters and videorecorded them in pairs, and later reflected on their experiences back in the classroom. The analysis focuses on co-constructed telling sequences through which novice L2 users reenact their experiences of interactions 'in the wild'. Building on earlier studies, we use the notion of 'the wild' (see Hutchins 1995) as a metaphor to refer to the complex and contingent nature of L2 speakers' social interactions outside the classroom. In sharing their experiences in the reflection phase, the participants employ a range of linguistic, embodied and technological resources (smart phone) to understand and resolve a problem of understanding that was experienced during the service encounter. Their orientation to the problem occasions a shift of focus to language-focused activity (Kasper \& Burch 2016) where the problem is clarified, analysed and elaborated retrospectively. Newly achieved understanding of the problematic practice - a responsive action by the clerk in the service encounter - is then woven into the narrative and the participants' alignments and affective stances vis a vis the reported and ongoing interaction.

We propose that the actions through which the participants display an orientation to an interactional practice as an object of learning and sustain this orientation beyond an interactional sequence can be analysed as a learning project. The notion of project is borrowed from Levinson $(2013,122)$, who uses it to describe a plan of action that at least one participant is pursuing in interaction. The analysis details how the participants collaboratively engage in such a project, whilst also performing a number of other actions 
in telling the story. Overall the analysis sheds new light on the ways in which the retrospective telling functions in the reflection phase of the experientially based pedagogical task. It shows how the telling generates opportunities for establishing and sustaining joint attention to, and playful testing of, L2 interactional resources by coconstructing narrative performance in a second language.

\section{Learning as interactionally contingent activity}

Language development is intrinsically tied to the coordinated courses of action through which various social activities are accomplished, and it is observable through a variety of actions that show participants' orientations to learning objects, to understanding or using something 'new' or recently learned (e.g. Pekarek Doehler 2010; Majlesi \& Broth 2012, Eskildsen \& Theodorsdottir 2015). This approach entails an understanding of cognition as distributed among the participants and publicly displayed in the coordinated sequences of action (Kasper \& Wagner 2011, Markee \& Seo 2009). A growing body of research describes how participants notice and attend to language, e.g. vocabulary (Markee 2008, Lilja 2014, Greer, 2013, Kasper \& Burch 2016), grammatical structures (e.g. Majlesi 2014) and interactional practices (e.g. Nguyen 2012 a \& b, Barraja-Rohan 2015) as objects of learning. These studies demonstrate how attention to language and moments of learning arise and are oriented to in the midst of pursuing other activities both inside and outside the classroom.

This study investigates learning as interactionally contingent activity by analysing the language users' retrospective tellings of their language use experiences outside the classroom while accomplishing a teacher-assigned task. The focus is on the participants' interactional investigation of a practice that they find problematic and the methods through which they seek to understand this practice during the telling. We propose that the situated actions through which the participants focus on the target practice provide a window into the social and embodied processes of learning in interaction (Pekarek Doehler 2010, see also Koschman 2013). Language practices must be understood in relation to "the grammar of actions" that they are part of (see Lee \& Hellermann 2014). In order to learn a word or a grammatical structure the learner must analyse and understand how that piece of language is used to accomplish meaningful actions in interaction. The case discussed in this paper demonstrates how the participants work to develop an understanding of the use of an interactional practice in a coordinated fashion. At the same time, they are engaged in co-constructing competent participation in storytelling within a L2 pedagogical context. This makes relevant specific kinds of competencies, including the ability to design actions so that they fit the current context of interaction and are understandable to co-participants. As previous studies demonstrate, storytelling demands skilled use of a range of interactional resources to construct extended turns through which participants display their state of knowledge and stance towards the events in the story, and engage in relationship work (see e.g. Stivers 2008, Hellermann 2008, Barraja-Rohan 2015; Wong 2015; Kasper \& Kim 2015, see also Pavlenko \& Lantolf 2000). This paper adds to these studies by examining how novice second language 
speakers of Finnish co-construct an embellished telling sequence and how the practices deployed in the telling furnish resources for detailed and embodied engagement with an interactional object of learning.

In the analysis to follow, specific attention is paid to reenactments and reported speech as resources in the telling sequences. Different forms of reported speech, their functions and design features have been studied extensively in previous linguistic and conversation analytic research (see Holt 1996, Clift \& Holt 2007, Couper-Kuhlen 2007, Berger \& Pekarek Doehler 2015, Prior 2015, Kasper \& Prior 2015). Direct reported speech and reenactments are closely related phenomena: both depict past events rather than describe them. Reenactments involve a shift in interactional footing whereby the speakers shift from reporting what someone said to actually playing or performing that character (see Holt 2007, Sidnell 2006; see also Goodwin 2007). They often implicitly or more explicitly reveal the stances of the current speaker towards the reenacted characters or happenings, whether real or hypothetical or imagined. In reenactments, the use of diverse bodily and other multimodal resources besides verbal utterances is central. For example, gaze direction is crucial for indicating that a reenactment is in progress (see Sidnell 2006). In this paper the interest is in the way that both verbal resources of reported speech and diverse bodily and other multimodal resources are used to accomplish actions that depict and reenact the events told about. As the analysis will show, reenactments can be accomplished through bodily resources only, and yet depict actions in the past interaction. The analysis focuses on the participants' displayed trouble with an interactional practice the use of a response particle in a service encounter setting - and the way this trouble is retrospectively analysed and transformed into an occasion for learning in classroom discussion. While the sequence in the service encounter unfolds without explicit attention to the troubled practice, the reenactment of the episode in the classroom creates an interactional space where the participants focus on it and clarify its use and import through coordinated action. The new understanding that is jointly developed in the course of the activity is consequential to the participants' understanding of the out-of-classroom experience as well as the way that the telling is co-constructed.

\section{Data and Methods}

The data for this paper comes from an ongoing project that aims to develop experiential pedagogy through activities and materials that support second language use in various everyday language use situations and guide students to reflect on their experiences of these interactions back in the classroom. The data were collected during three different courses on conversational Finnish aimed for beginning learners. The goal of the courses was to develop the learners' oral skills by using real-life communicative tasks and guided reflection of out-of-classroom experiences. At the beginning of the course, students' needs and everyday experiences in the L2 community were explored using a mapping activity (see also Wagner 2015). This served as the starting point for discussing the students' individual learning objectives and for developing two out-of-classroom activities that 
involved participating in service encounters in a local network of businesses ${ }^{1}$. The service providers had been contacted beforehand and they had agreed to join the network and also given their consent for being videorecorded by the learners.

The structure of the learning activities followed a three-part pedagogical model (cf. Clark \& Lindeman 2011). First, the students prepared for the interactions 'in the wild' by observing them and planning their language use. In the preparation phase, they were instructed to take part in the service encounter of their choice and ask one or two questions in addition to conducting their business. Next, the students participated in the interactions in pairs and video-recorded them with their own smartphones or tablets. Third, back in the classroom the students shared their experiences in small groups, watched the videos of the interactions and reflected upon them. The teachers provided questions to guide the retrospective discussions. The students were asked to discuss what happened, how they felt about the task, whether anything unusual or surprising happened, whether they experienced problems and how the problems were solved (a list of the questions is provided in appendix 2).

The primary data for this paper comprises the videorecording of the service encounter in focus and the small group discussion back in the classroom. The data is drawn from a larger corpus of altogether 41 service encounters and 11 small group discussions (12 hours 21 minutes) in the classroom ${ }^{2}$. In addition, observational data were collected in the classroom. The researchers were present in the lessons and discussed their observations with the teachers of the three courses. The group discussions followed roughly the same kind of structure: each student told about his or her interaction, after which the participants usually watched the video together. The tellings typically set up an activity frame for watching the video, which enabled the students to focus on some part of the interaction that they found interesting or problematic. Here, we focus on one group of students in which John, Mark and Anne talk about John's experience in a cafe. The service encounter was witnessed by Mark, who also recorded it on his smart phone. As the data will show, John and Mark treated the task creatively: instead of asking only questions related to the specific service encounter, John expands the sequence by asking whether the young woman (= the clerk) would like to go out on a date. Although no videorecorded data is available from the planning session before the encounter, details of interaction in the service encounter (e.g. the fluent delivery of the turn initiating the sequence) support the interpretation that the question was not entirely spontaneous (see extract $1 \mathrm{~b}$ below).

The data is analysed using multimodal conversation analysis (see e.g. Mondada 2014a). The analysis focuses on how different linguistic, embodied and material resources, such as gestures, gaze, body movements, prosody and smart phones, are assembled to reenact the events being told. The data has been transcribed according to the conventions of CA and the conventions for multimodal transcription developed by Mondada (2014b). Still photos (frame grabs) from the videos illustrate the use of different

\footnotetext{
${ }^{1}$ The network of service providers included cafés at University, a paper shop, a restaurant, a bicycle repair shop, hairdressers and a tourist information office.

${ }^{2}$ And 8 hours 43 minutes of discussions during which the students prepare for the interactions outside the classroom (i.e. the first phase of the pedagogical model).
} 
resources during telling and changes in the body postures and gestures of the participants when relevant for the analysis.

\section{Analysis}

In what follows we analyse students' in situ practices during the teacher-assigned learning task. We begin with observations on John's service encounter in a cafe, and then present a detailed analysis of how this event was represented in the classroom. In the analysis of the reflective discussion, we focus on John's reenactment of the situation and elucidate how it serves as a method for the participants to establish joint attention to an interactional practice that caused a problem of understanding in the service encounter. The coconstructed, embellished telling of the experience engenders an extended languagefocused activity where the participants work to develop an understanding of the practice in focus.

\section{The service encounter}

Extract 1 shows John's service encounter at a University café. At first the encounter proceeds in a routine-like manner: John orders a coffee (1. 1), the clerk (C) receives the order with a routine response (kiitos) and asks a follow-up question (1. 3). In spite of John's negative response (1.5) the clerk pursues the activity with a multimodally achieved offer: she draws John's attention to a box of chocolates placed on the counter by directing her gaze and reaching her hand towards the chocolates. She then references the chocolates as a Valentine's day delicacy and simultaneously touches the sign next to them and turns her gaze to John (1. 7). Meanwhile, John is occupied with pouring himself a cup of coffee from a pot also on the counter.

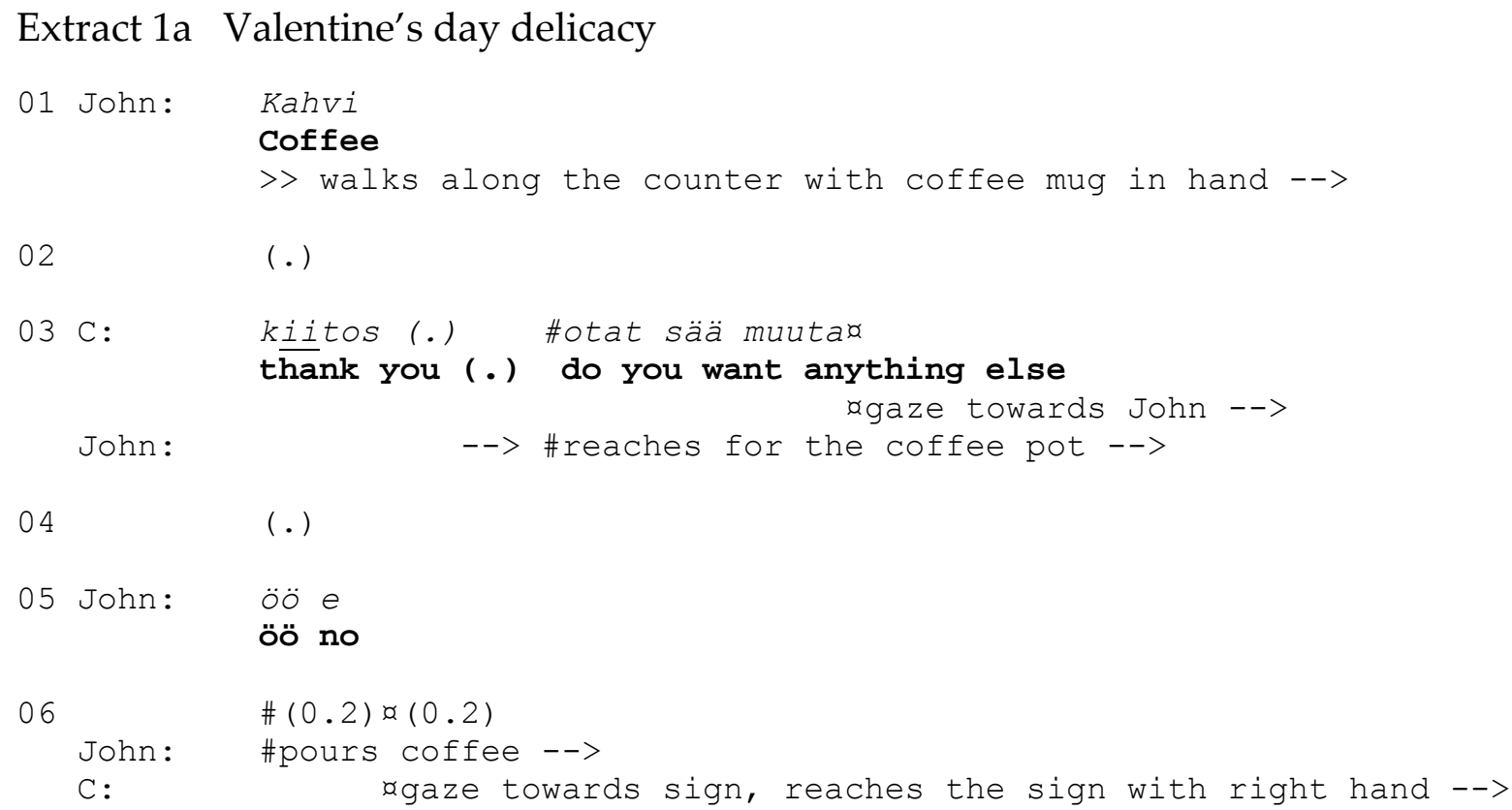


John :

mitä on?\#

what is

what is it?

$-->$ \#

09

$($.

$10 \mathrm{C}$ :

$>$ ne on< $\uparrow$ suukkoja

$>$ they are< kisses

11 John: \# joo \#
yes
$\#$ nods

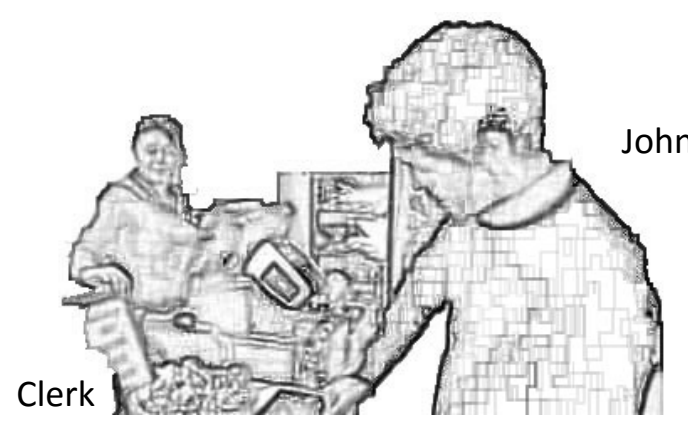

FIG 1.

\# smiles gaze down --->

12 a \# (1.2)

John: -->\# smiles and moves a few steps along the counter -->

C: asmiles -->>

13 John: *missä on kerma (.) ah (.) \# >tässä<

where is the cream (.) ah (.) >here<

$->*$ gazes down on the counter \#reaches for the cream

The clerk's offer occasions an insert sequence, where the clerk, in response to John's information seeking question, produces the name of the chocolate product: suukkoja (kisses). At this point both begin to smile. However, John is not tempted by the offer. Instead, he acknowledges it (1.11) and proceeds to ask where the cream for the coffee is. After John's physical activities focused on the coffee and cream are finished, the participants move to the closing phase of the service encounter: the payment (lines 22-24). However, instead of closing the sequence, John then initiates a new sequence with a question that markedly departs from the service encounter routine: he asks the clerk out on a date (1. 26). This action shows signs of John and Mark's creative approach to the teacher-assigned task.

\section{Extract 1b, John's question}

22 C: kiitos (.) elikkä euro ja ( - ) senttiä

thanks (.) it is euro and (-) cents then

23 John: $\quad(\sim 6.0)$ ( (pays with a card))

$24 \mathrm{C}$ : akitos (.) kuittia tarvitko (0.4) a o >ole [hyvä< thank you (.) do you need the check (0.4) >here [you are<

a gaze towards John, touches the cash machine with right hando whands receipt to Johno 


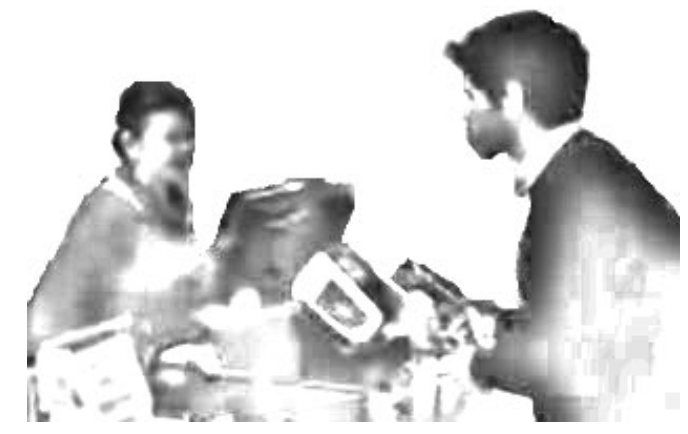

FIG 2

26 John:

\#ää haluaisitko lähteä joskus öö (.) [ aulos want-COND-2SG-CLI go sometimes out (-) ää would you like to go out sometime (.) $-->\#$ FIG 2

$27 \mathrm{C}:$

28

C :

29 C:

30 John:

31

32 John:

$\quad$ \#no nähdään myöhemmin

\section{well see you later}

\#walks away, waves hand towards clerk again

$33 \mathrm{C}: \quad$ kitos

thank you

34 John: kitos

thank you

Here we can note that John's question (1.26) is fluent and well-formed: a conventionally polite conditional verb form is used, and there are no speech perturbations or clear signs of trouble ${ }^{3}$. This suggests that the question may have been considered, if not planned, by John and Mark prior to participating in the encounter as a playful alternative to routine

${ }^{3}$ We interpret the vocalisations 'ää' and 'öö' as turn-organisational devices. 
questions ${ }^{4}$. Yet it is also occasioned by the local contingencies of the activity in its temporal, social and material environment. The clerks' actions that reference the special offer, including the product name with its romantic association, make relevant the larger context of Valentine's Day and occasion a brief moment of shared affect. The mutual smiling may also display orientation to the sensitivity to the situation. Although the participants disengage from the affective moment and move to the payment sequence, an opportunity to re-engage arises when the clerk is handing over the receipt to John. For this the participants move physically closer and direct gaze towards each other. It is in this context that John's sequence-expanding question becomes askable (on askability of questions, see Stivers 2011).

The clerk responds to the question with the response particle oikeesti? (1. 29). In its sequential and activity context the particle questions the sincerity of John's turn: the clerk wants to know if he is serious about asking her out. It thus indicates that the clerk has trouble in deciding how to treat John's turn. The particle oikeesti expresses ritualized disbelief (cf. Heritage 1984, Wilkinson \& Kitzinger 2006) and conveys the stance of the clerk. At the same time her embodied actions prior to the verbal response (a head movement, chuckle and nodding, 1.27 - 28) express affect. The verbal turn invites a response, minimally a confirmation, from the other participant (Thompson, Fox \& CouperKuhlen 2015).

John reacts to this by repeating the response particle with falling intonation (1. 30). In this sequential environment, the repetition is a possible way to confirm the previous turn. Structurally these two turns form an insert expansion after which (in line 31) an answer to the original question is still conditionally relevant (see Schegloff 2007: 97106). However, John does not wait for the answer, but produces a vocalization followed by a closing-relevant utterance ('see you later', 1. 32), and rushes away from the situation. The rushed closing of the sequence (1.32-34) indicates trouble potentially caused by a problem in understanding the meaning of the response particle. However, the trouble may also be related to the non-routinized and potentially sensitive nature of the situation. Features of the physical environment may also have bearing on John's conduct: other customers approach the counter and a line is beginning to form behind John, making it more difficult for him to extend the interaction further.

John's question and the clerk's response became the focal point in John's telling about his interaction back in the classroom. In the following we analyse how John's reenactment of this experience in a group discussion draws the participants' mutual attention to the clerk's response and the particle oikeesti as a source of trouble and creates a space for treating it as an object of learning. The actions through which the participants establish and sustain focus on this practice and work towards a new understanding of it make visible the participants' orientation to a learning project.

\section{Framing the telling}

\footnotetext{
4 Unfortunately detailed information on the preparation phase is not available for analysis. However, from the classroom data it is clear that the topic of dates or Valentine's day was not discussed in class prior to this task.
} 
Back in the classroom John begins his telling by foregrounding the mundane character of the service encounter he had. His embodied activity (direction of gaze, gesture in Fig. 3) shows that the principal recipient of the story is Anne, who (unlike Mark) did not witness the actual encounter.

\section{Extract 2: John begins telling}

01 John:

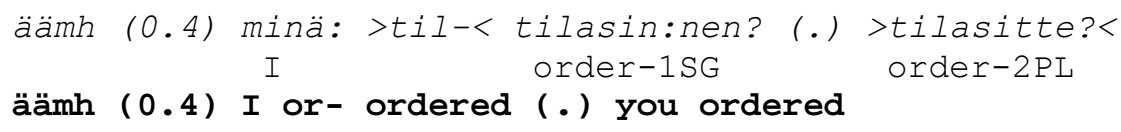

06 John:

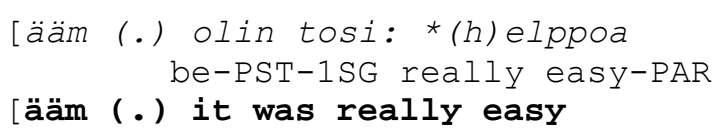

07

$\quad+()+$.

08 John: joo?*

yes

$-->$ *gaze down -->

09 John:

. $\mathrm{hh}$

ääm, (0.8) normaali: kysymys öö: [(.)

.hh ääm (0.8) normal question öö: $[()$.

10 Mark: $\left[{ }^{\circ} \mathrm{eh} \mathrm{he} \mathrm{e}^{\circ}\right.$

11 John:

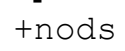

+nods

12 Anne: $\quad \stackrel{9 m m}{+}+\left[\mathrm{hm}^{\circ}\right.$

13 John: [ääm mutta: (0.4).hh ääm: (0.6).hh ähm:

[ ääm but: $(0.4)$.hh ääm: $(0.6)$.hh ähm:

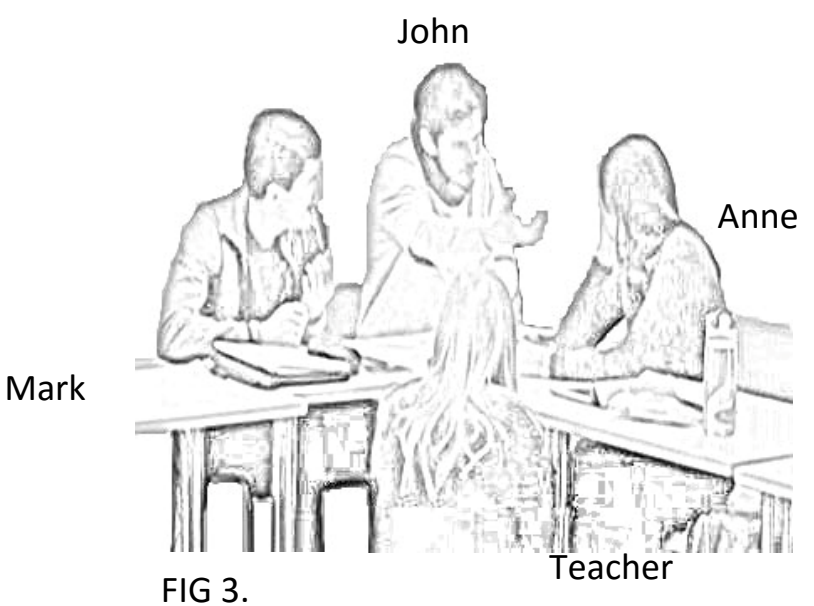

FIG 3. 


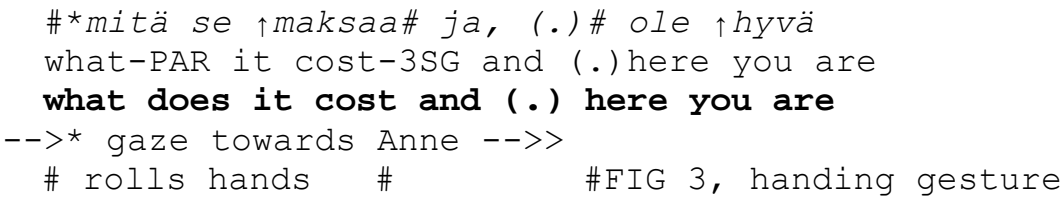

16 Anne: $\mathbf{m h m}$

John prefaces his telling by describing the situation as easy (1. 6) and characterising the questions asked as normal (1.9). The noun phrase normaali kysymys (normal question) introduces a series of utterances that represent the talk of a customer in a service encounter. First John enacts a request for a coffee and then enquires about its price (1. 11). He continues with a turn unit initiated with the contrastive conjunction mutta (but), followed by a construction approximating a reporting clause (line 14). However, instead of the verb (kysyä-ask), John uses a noun (kysymys). After that he repeats the question about the price and articulates the phrase ole hyvä (here you are, 1. 15) accompanied with a gesture: he stretches his right arm forward (see fig. 3). With this action he enacts the gestures of a clerk handing the customer something and marks a shift from narrating to enacting a hypothetical or "a typical" service encounter.

It is noteworthy that the reported verbal exchange did not actually take place in the service encounter. Rather than depicting what actually happened, the function of the represented talk in this extract is to highlight the mundane character of the encounter in order to set the scene for the climax of the story. The reporting of the phrases that are routinely used in service encounters depicts the event as typical and in no way out of the ordinary. Already at this point Mark, who witnessed the encounter, reacts to the telling with laughter (1.10). With this he displays his knowledge of the events told about (Goodwin 1986) and also his stance towards them.

\section{Representing the question and the clerk's response}

In extract 3 John moves from the schematic depiction of the service encounter to reporting about the sequence-expanding question he asked. The represented question markedly contrasts with the way the interaction was depicted in prior turns: asking the clerk out is not a routine part of a typical and uneventful service encounter that John has just constructed. Therefore, it sets up a new and surprising frame for interpreting the story under way.

\section{Extract 3: John's question}

17 John: *ää, (1.2) ää en, (.) ja, (.) minä kysymy- mä kysymys ääm: ää (1.2) ää I don't (.) and (.) I quest- I question ääm: * gaze down towards table --> 
contrast that John constructs between the representation of the question and his earlier characterisation of the mundane service encounter is designed to attract heightened participation from the recipients. While Mark receives the represented question with laughter (line 20), Anne's reaction is minimal (line 21). John's next turn, which translates the question into English, treats Anne's response as insufficient. The act of translating seems to show orientation to making the focal action understandable to Anne as the recipient in preparation for the climax of the story. This turn succeeds in inviting a stronger reaction from Anne: she acknowledges the turn, laughs, gazes towards the teacher and holds her hand over her mouth (see fig 4). All in all, her embodied response now clearly shows appreciation of the question as out of the ordinary. While both Anne and Mark are laughing, John makes interactional efforts to continue the telling with a turninitial conjunction and, followed by embodied actions (vocalization, pointing gesture, gaze down) and the conjunction ja (and) in Finnish (Kurhila 2006, Mondada 2007).

The reporting of the question creates an expectation that the next part of the story is going to deal with the answer. In extract $4 \mathrm{a}$ this is observable in lines 28 and 30, where Mark becomes a co-teller and articulates three reporting clauses: the first two in Finnish and the third in English. These indicate that Mark orients to reporting about the answer as the next relevant part of the story and the storytelling activity as a joint endeavor (Lerner 1992).
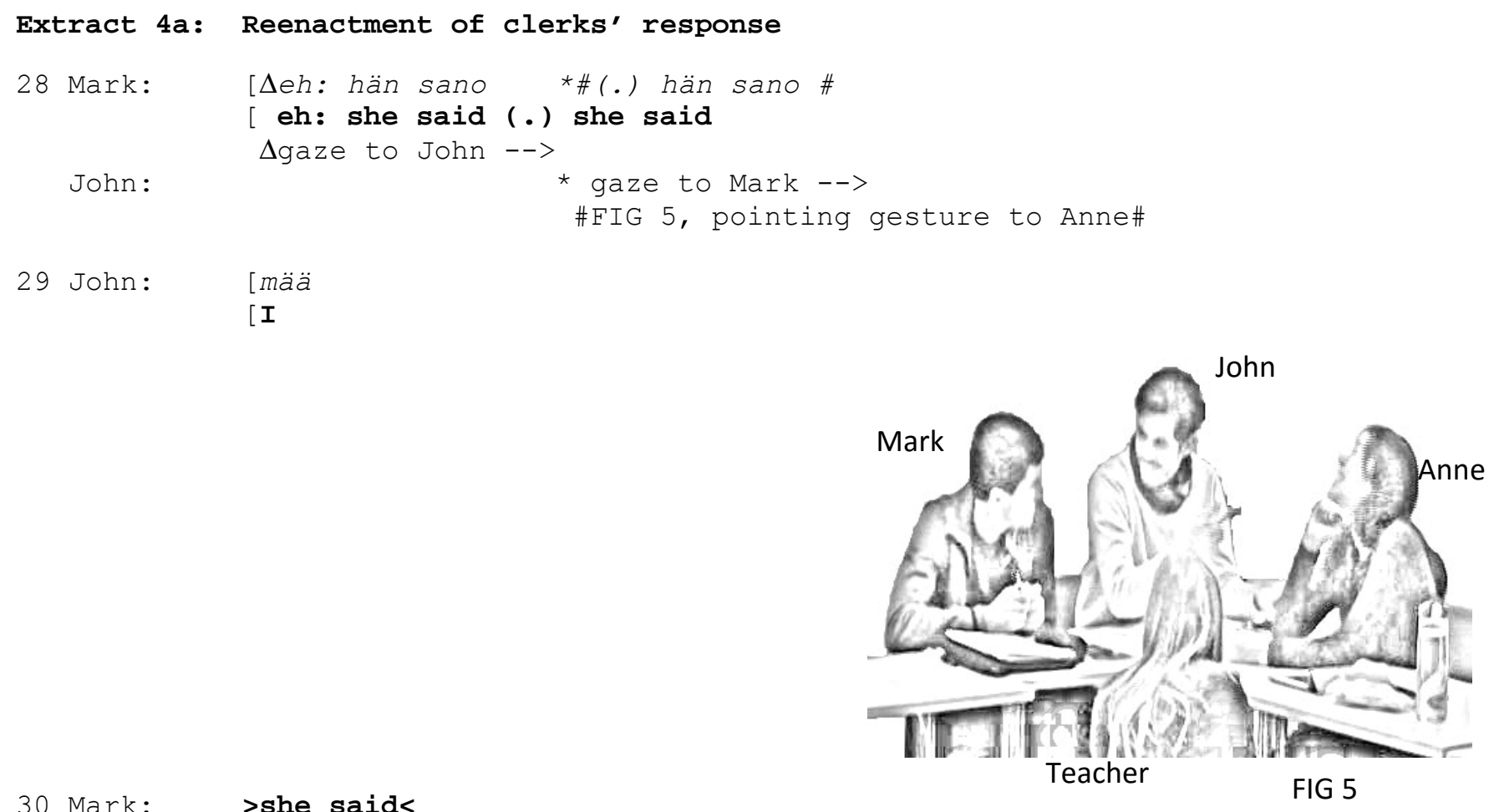


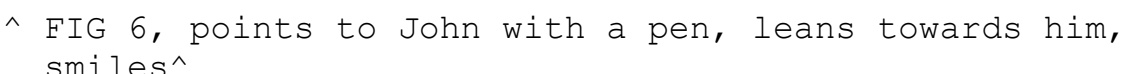
smiles^

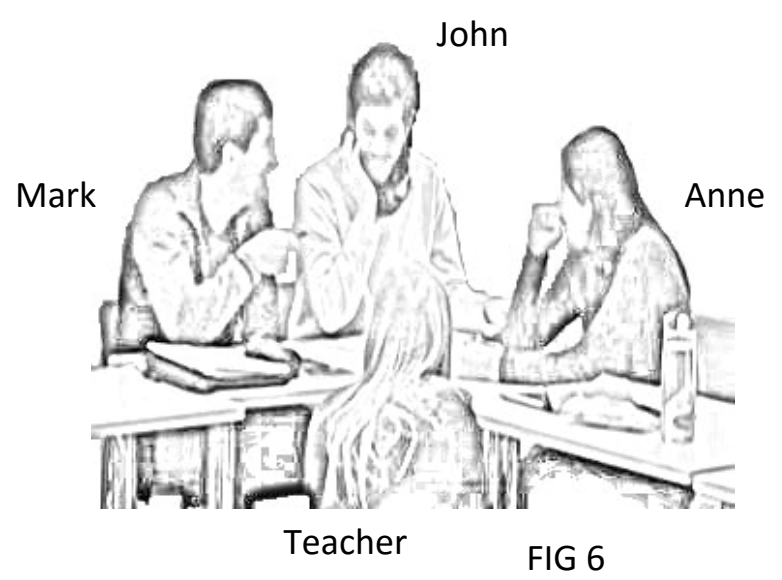

Also John produces a reporting clause in Finnish, but shows difficulty with continuing the story (visible in the micropause and perturbation, 1. 31). At this point Mark intervenes with a comment claiming that John does not actually know what the clerk said (1. 32). The turn is produced with laughter and accompanied with a pointing gesture directed at John. It is thus hearable as a teasing remark which draws attention to the trouble created by the clerk's response and John's apparent lack of competence in the reported event.

John continues the story by producing the reporting clause again twice (lines $33,35)$. After these he does not, however, continue the turn verbally but instead reenacts the clerk's response (1. 35-40).

\section{Extract 4b: Reenactment of clerks' response}

$\begin{aligned} 33 \text { John: } & \text { [hän sano } \\ & {[\text { she said }}\end{aligned}$

34 Mark: eh heh $[>(m e)<$

eh heh [ (we)

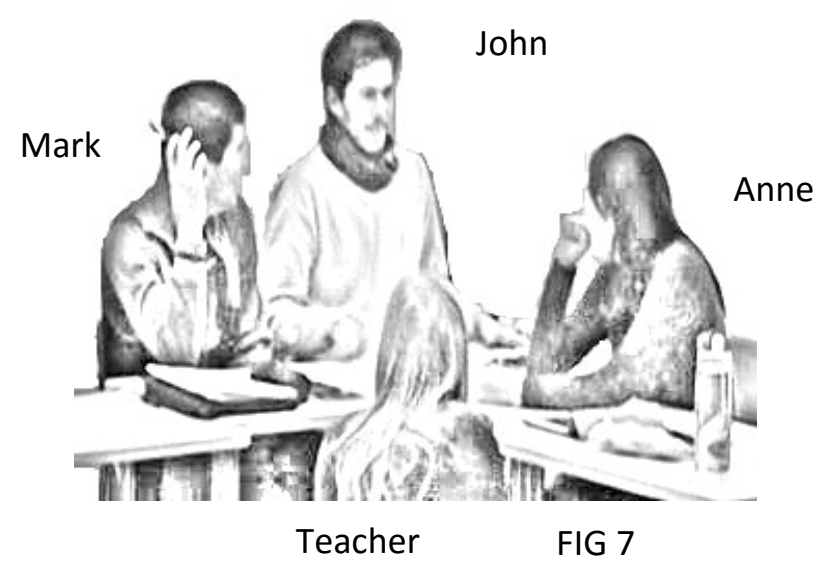




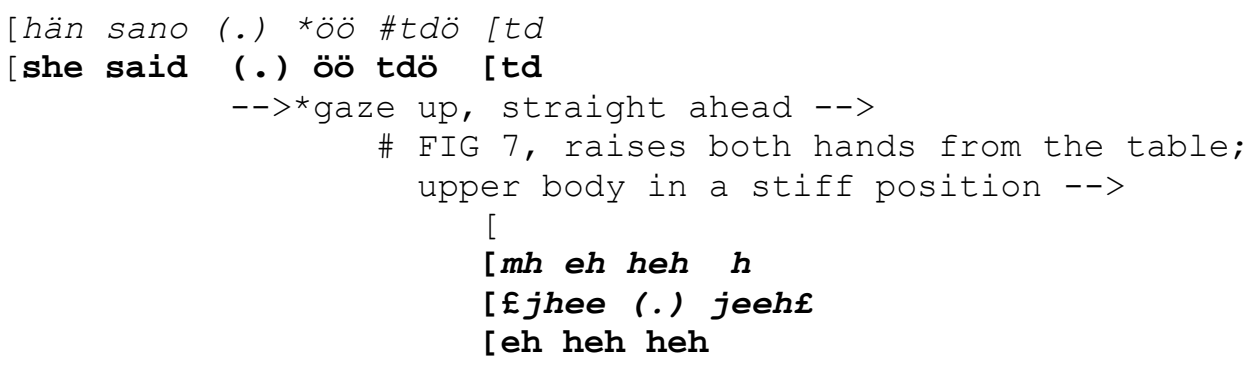

[£jhee (.) jeeh£

[eh heh heh

36 Anne:

38 Tea:

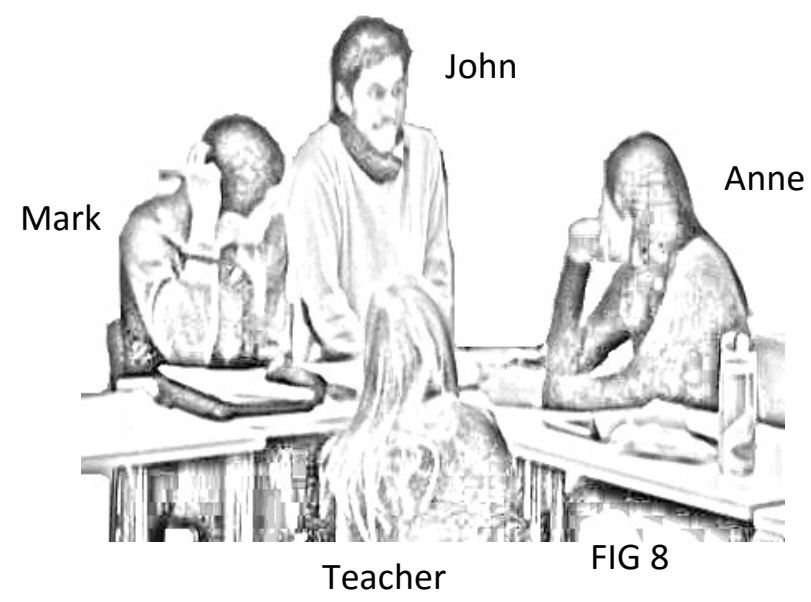

39 Mark: [eh eh eh

40 John: [\#eh eh: \#\#*eh:

-->\#moves hands from table to lap\#\# FIG 8., raises shoulders and eyebrows $-->$

*gazes towards Anne -->

\section{Anne: [eh heh heh}

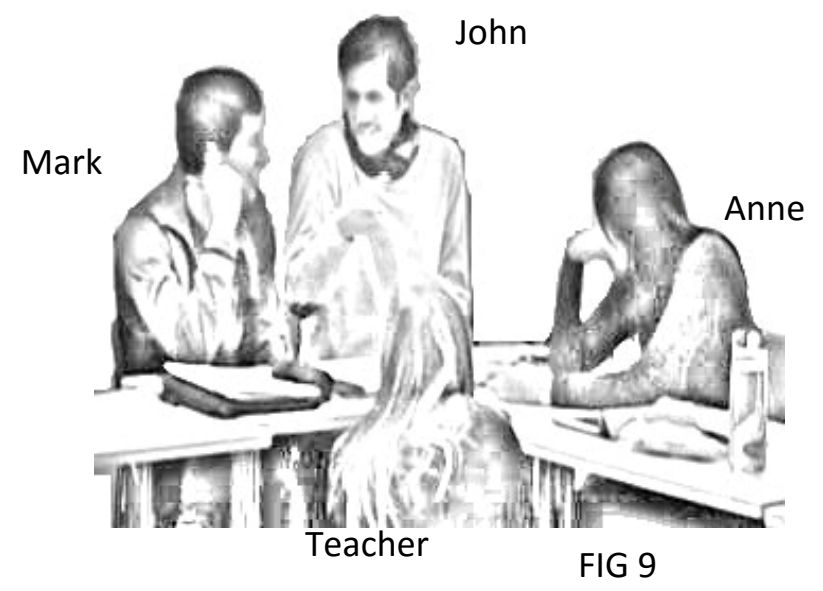

43 Anne: [ih heh heh

44 John:

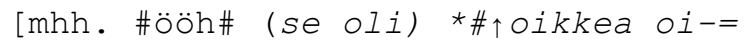
(it was) right ri-=

\#nods\# - ->*\#FIG9, turns gaze towards Mark; shakes right hand $-->$ 

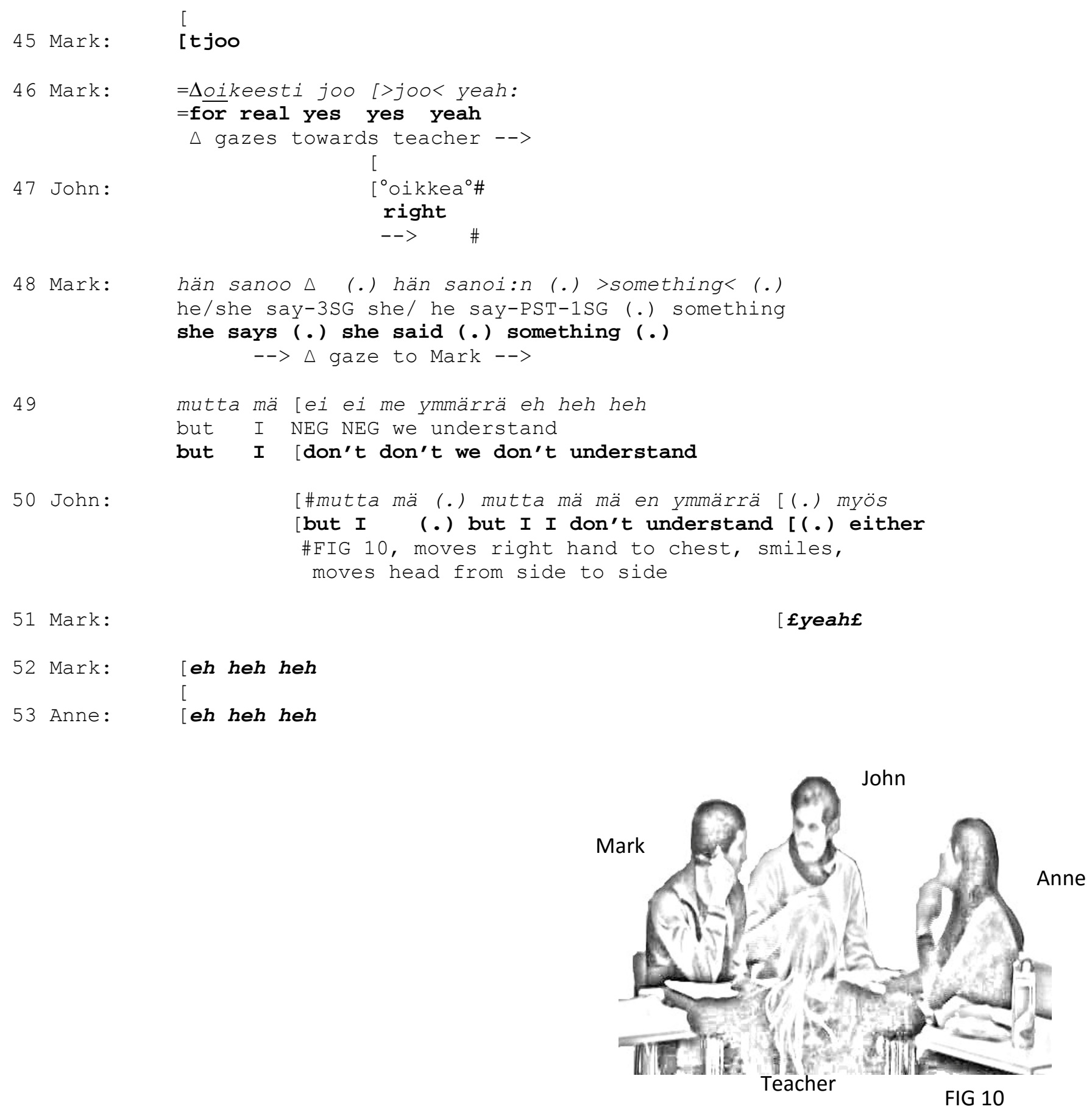

The reenactment consists of two parts, achieved through two different configurations of body position and gestures, and enables subtle shifts in the telling which represent and dramatize the participants' stances in the depicted situation. First, in line 35, as John begins to enact the situation, he takes a stiff position and raises both hands from the table (fig 7). This bodily configuration together with his facial expression and vocalizations displays surprise. He looks straight ahead, but does not engage in eye contact with any of the co-participants even though they gaze towards him (see Sidnell 2006).

A reenactment always represents the reported events from a particular perspective. Here John's reenactment is positioned after a reporting clause that projects 
reproduction of the answer given by the clerk. In addition, the reenactment conveys surprise and disbelief. These cues suggest that John here re-enacts the events from the clerk's perspective and enacts her stances in the situation.

Another gestural shift occurs as John raises his shoulders, moves his hands from above the table to his lap, raises his eyebrows and turns gaze towards Anne so as to enlist her participation (see line 40, fig 8). The posture is held throughout Anne's reaction (1. 43) and performs a conventional, here exaggerated, stance of puzzlement. With the body shift John seems to perform and dramatize the stance embodied by the clerk's response. Even though the verbal response is not reproduced, the reenactment captures the ritual disbelief expressed by oikeesti and the way that it puts an answer to John's question on hold.

All in all, John's reenactment constructs the clerk's reaction as exciting and, accordingly, contributes to making the story interesting and worth telling (see also Sidnell 2006). What is more, the reenactment captures the affective level of the interaction and conveys the emotions involved in a more dramatic and perhaps more recognizable way than merely reproducing the verbal contents of the answer would have done. In this sense, the reenactment is an expressive way to communicate what was experienced in the toldabout-situation. The reenactment catches the attention of the co-participants, who are gazing towards John and react to the telling with shared laughter (lines 36-43). The heightened attention of all participants establishes an environment where further talk focusing on the clerk's response becomes interactionally relevant.

In line 44 John turns his gaze towards Mark, initiates a word search and draws on both verbal and gestural resources to produce an approximate for the lexical response particle used in the actual service encounter. The change in the bodily configuration and gaze direction indicates that the reenactment is over. In the next turn, Mark reproduces the exact response particle the clerk used (line 46). Next, the particle is established as a source of trouble in the service encounter: Mark reports that the clerk said "something" but they did not understand it (line 48-49) and John aligns with this by emphasizing his non-understanding (1.50).

In sum, at this point John has set up the clerk's response (i.e. the particle oikeesti) as the focal point of his telling. John's reenactment highlights the situation as out of the ordinary and draws attention to the problem of understanding and puzzlement experienced in the situation. Through the reenactment John is able to reconstruct the situation, including the interactional trouble experienced in it, as a skilled performance that contrasts with the lack of linguistic resources evident both in the service encounter and its retelling. Even if Mark is able to reproduce the whole particle oikeesti, both he and John have explicated their non-understanding of its meaning in the situation. This engenders a shift to language-focused activity. Next, the participants set out to scrutinize the problem by starting to watch the videorecording of the service encounter. 


\section{Watching the video}

John's telling has constructed the clerk's action as the climax of the story. The sequence continues with further claims of not understanding, accompanied with laughter from both John and Mark (data not shown). This sets up an interactional environment for watching the video of the problematic episode, which is recorded on John's smart phone. Extract 5 shows how the participants visibly orient to the problematic part of the interaction on the video: as soon as they hear the clerk's turn, Mark repeats it (1. 3) and John asks what it means (1. 5).

\section{Extract 5: repeating the reaction}

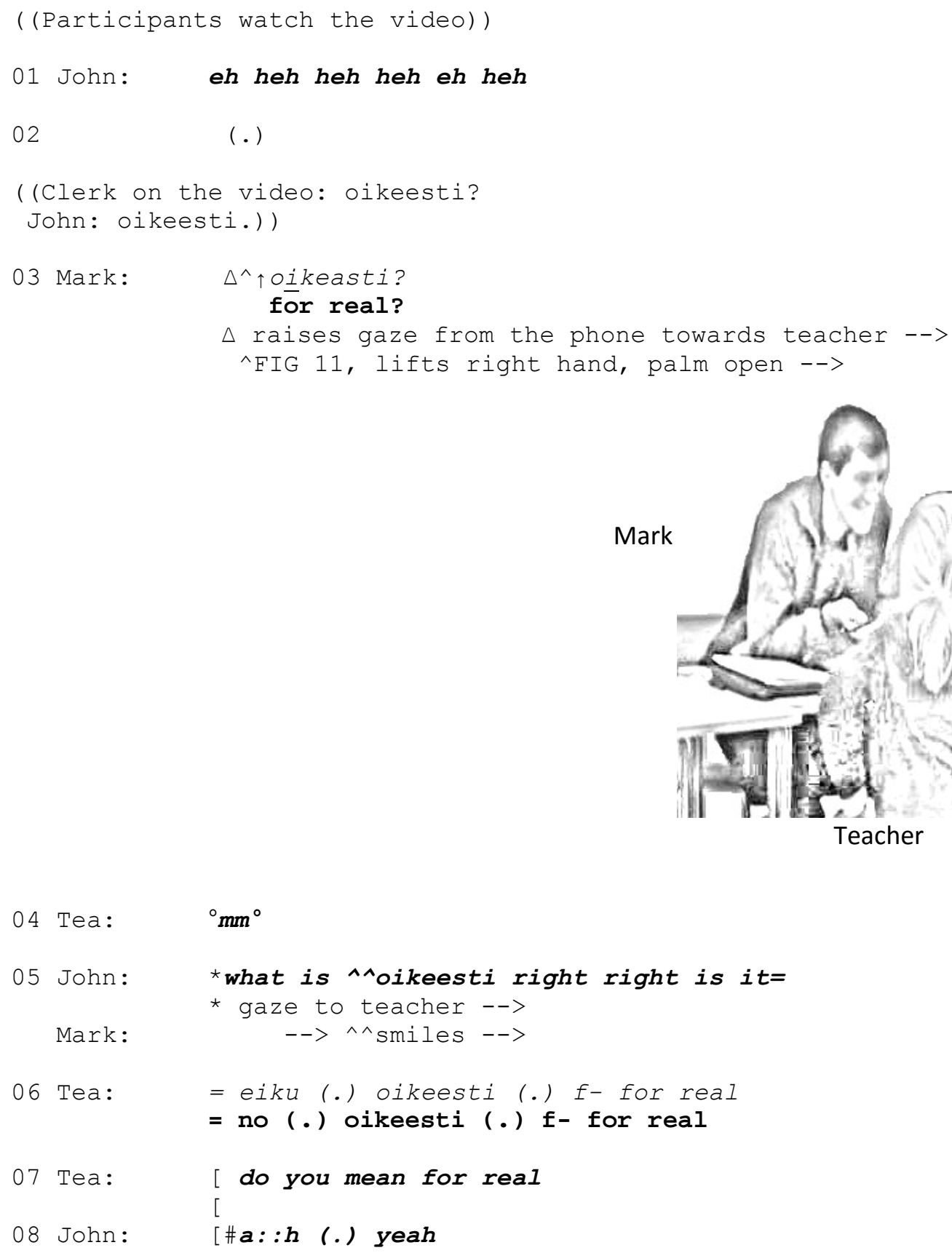




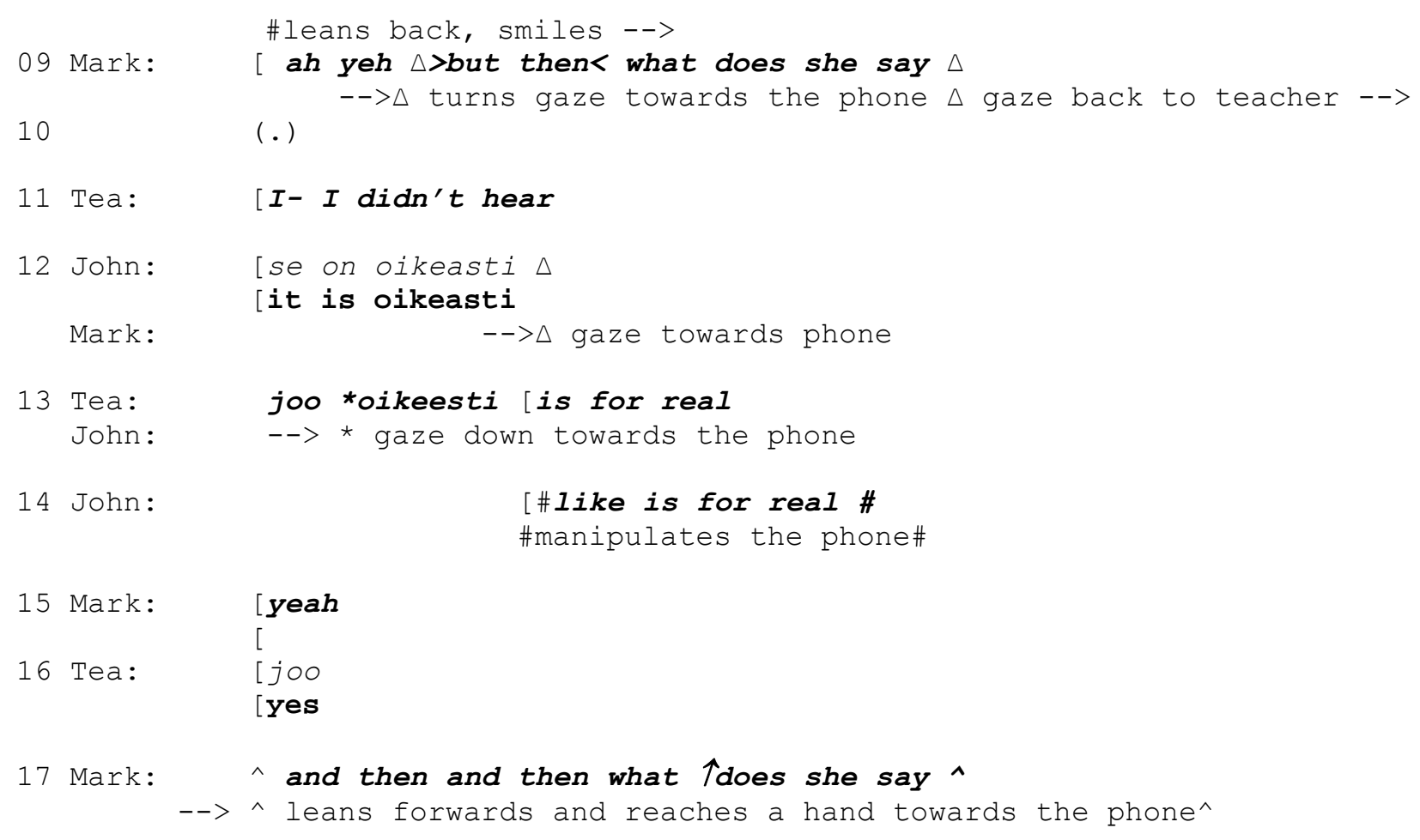

The focus of the shared watching of the video is thus clearly on the clerks' turn, and both Mark and John orient to understanding its meaning. Mark's repetition highlights the target expression: it is delivered with slightly emphatic prosody (high onset) and it reproduces the target expression in a standard form (oikeasti), which contrasts with the clerk's colloquial use (oikeesti). Further, through its embodied features - gaze and an open palm hand gesture - the turn addresses the teacher and seeks confirmation for Mark's hearing of the expression. John's question following the teacher's minimal response (line 5) seeks to clarify the meaning of the response particle: it suggests a possible translation (right) and seeks confirmation for it. In line 6, the teacher corrects this understanding and offers a different translation: for real, do you mean for real. Interestingly, this translation captures the interactional use of the particle (i.e. its import as an action that initiates an insert sequence). However, it does not capture the nuanced situational meaning of the particle in the same specificity as John's reenactment did. Both Mark and John receive the information given by the teacher with a change of state particle aah (lines 8,9), thereby claiming a new understanding of it (Koivisto 2015). However, Mark's question in line 9 still requests further clarification and pursues the project of understanding the target practice. The teacher declines to answer his question with an account (line 11), while John repeats the clerk's expression in standard form (line 12). During these overlapping turns, both John and Mark's embodied orientation shifts towards the phone, suggesting a change of orientation towards the video. The teacher's next turn performs an embedded correction (Jefferson 1987) of John's repetition by producing the expression in the colloquial form, followed by a translation which is jointly constructed with John (line 14) and then confirmed by Mark and the teacher in overlap (lines 15 -16). The retrospective talk about the form and meaning of the target expression is focused on understanding and 
learning not just the linguistic item, but also how the response particle was used in the service encounter.

Having clarified the meaning of the target expression and established that it did not constitute an answer to John's question, the participants' interest now turns to what happens next in the encounter. They re-engage in watching the video and continue to pursue the learning project. Again, as soon as the target sequence is heard, John repeats the expression (line 18).

\section{Extract 6: Watching the video again}

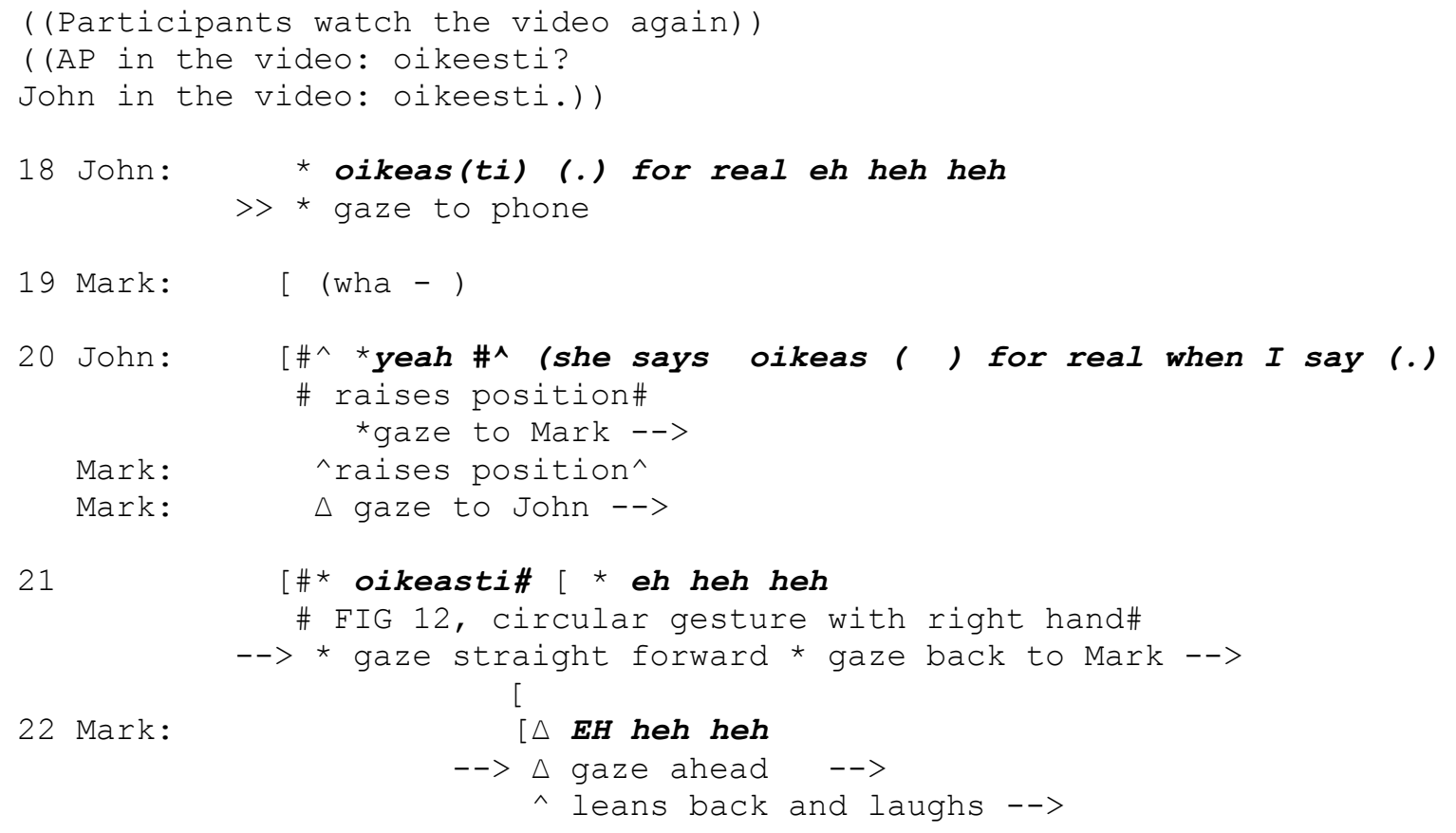

24 Mark:

[eh heh heh

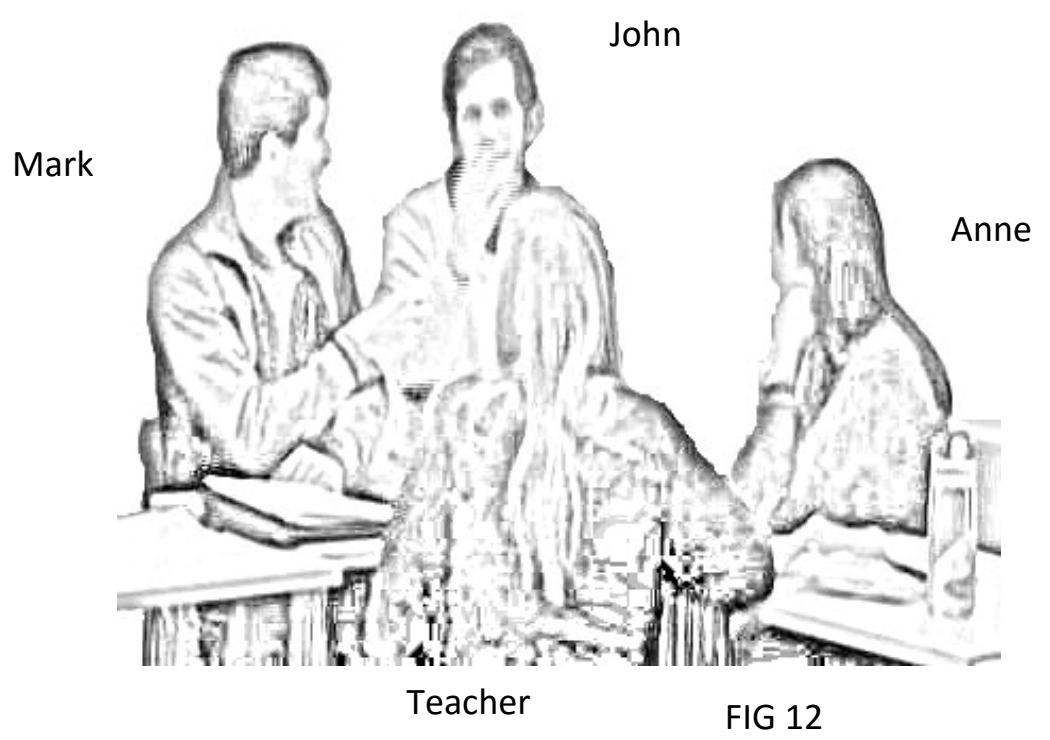


Following the repetition, John reports the clerk's response and also reiterates its meaning (in lines 20 -21). These actions function to maintain the participant's shared focus on the answer and reconfirm its meaning and use even after the word has already been clarified. At this point the clerk's turn is thus no longer treated as a source of trouble. Instead, it becomes a source of amusement and is embellished to build the narrative. This is achieved through embodied activity: John shifts his gaze away from Mark for a while (1. 21), and initiates an expressive waving hand gesture which is performed in coordination with the target utterance (line 21). The hand gesture seems to depict an attitude of nonchalance and charm and reenact John's own stance in the encounter. The return of his gaze to Mark towards the end of this action invites a laughing response from Mark and the two engage in joint laughter, during which John performs another, even more elaborate gesture waving and circling his right hand (1. 23). The reenactment performed after reconfirming the clerk's utterance highlights John's own performance in the encounter and constructs a colorful representation of it for humorous and dramatic effect. It occasions a moment of affective engagement between John and Mark, displayed through mutual gaze, laughter and alignment of their bodies. This embodied narrative performance enables John to construct himself as a competent teller capable of performing complex stances and identity work in a second language.

Watching the video does not resolve the issue of what happened next, i.e. whether John's question was answered. Mark turns his focus to this in his question in line 26. After John reports that she did not say anything, Mark accepts the answer and engages in more laughter, with Anne joining in (1.29-30). At this point John repeats the target utterance and its translation once more (1.32) and after receiving confirmation from both the teacher and Mark, also playfully experiments with the meaning of the particle (1. 36).

\section{Extract 7}

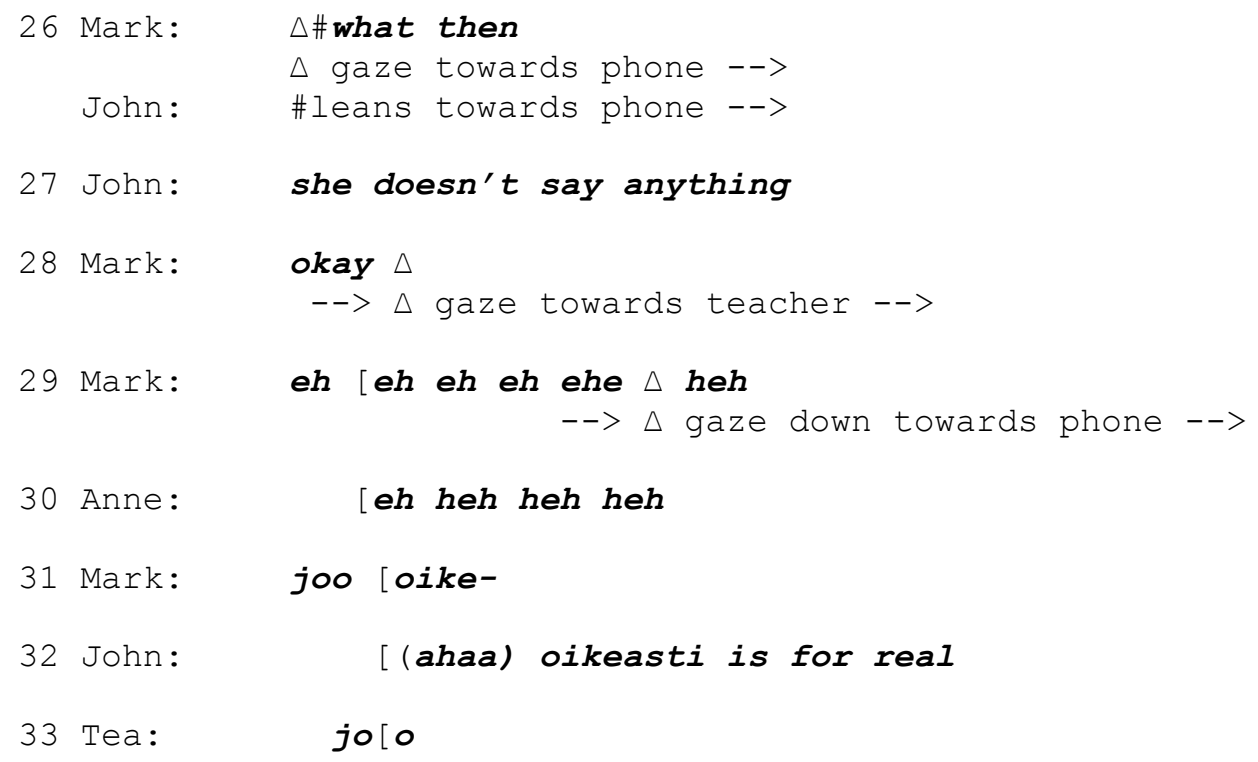




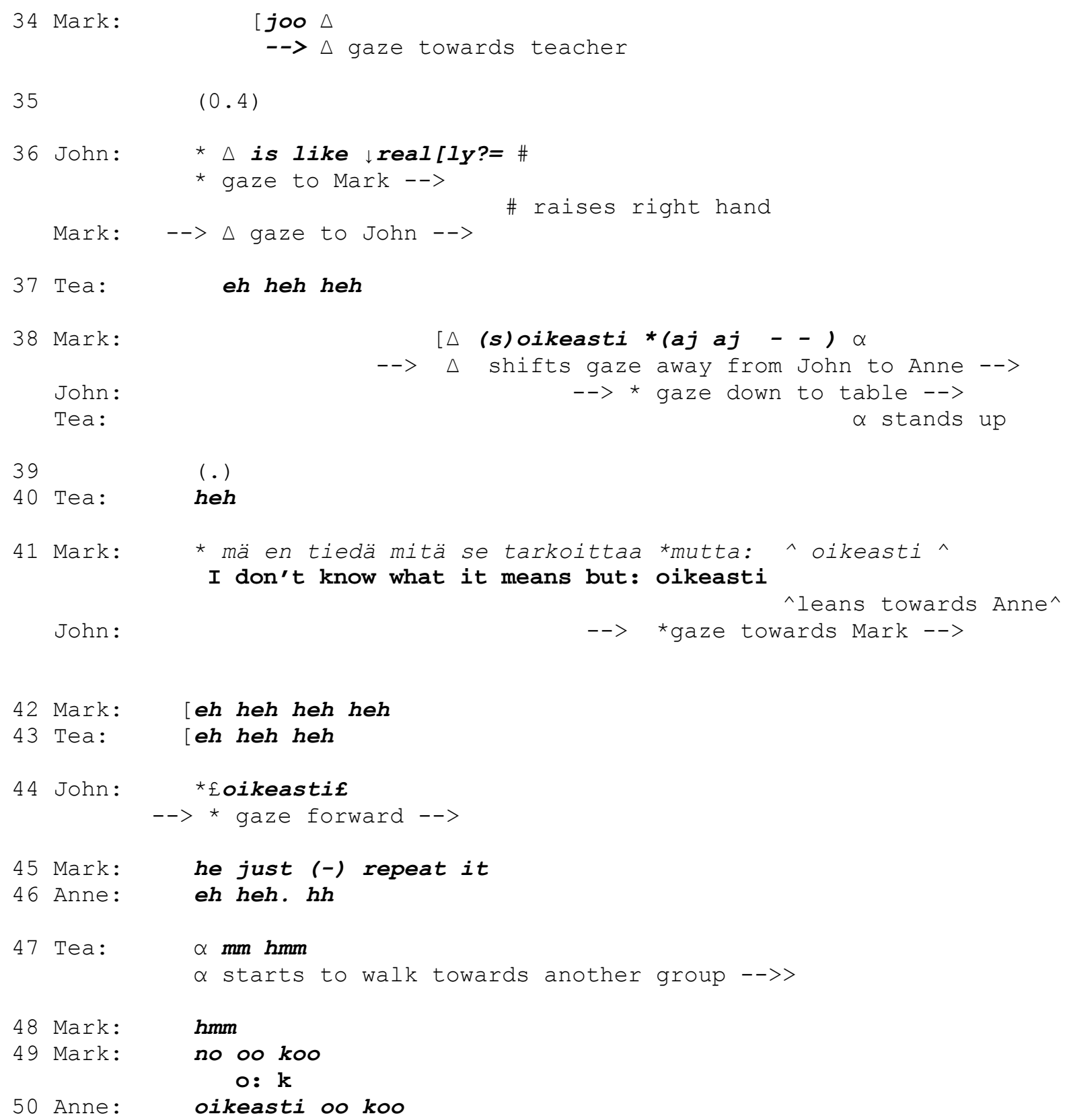

John's turn (1.36) again embellishes the clerk's response through exaggerated prosody and facial expression as well as an accompanying hand gesture (raising the right hand). Through gaze John treats Mark as the primary recipient in his performance and also invites co-participation. The embellishment generates laughter from the teacher $(1.37,40)$, while Mark joins in John's telling. A shift in the participation framework (e.g. Goodwin 1984, 2007) is accomplished when he withdraws his gaze from John, while repeating the expression once more (1.38). Gazing towards Anne, Mark then shifts footing and continues the telling from John's perspective: speaking in first person, he apparently voices John's thoughts in the problematic situation (1.41). With this he draws attention to John's action of repeating the clerk's expression without understanding it. This is further explicated by his repetition and comment in line 45. Here Mark refers to John in third person, which contributes to constructing his talk as teasing (see Margutti 2007: 643-646). 
Accordingly, Anne and the teacher respond with laughter (1. 46-47). This moves the telling towards closing: Mark withdraws his gaze from the other participants, and John and the teacher also disengage from the interaction. Mark's closing-relevant 'ok' (1. 49) is followed by Anne's repetition of the response particle and confirmation (1.50). Anne's turn displays her orientation to the focal expression as a newly understood object of learning. With this action the occasioned learning project is playfully brought to completion.

\section{Discussion}

This paper has investigated how a teacher-assigned learning task designed to bridge language use situations inside and outside the classroom generates occasions for learning in interaction. The analysis shows how the re-enactment of an out-of-classroom L2 use experience enabled an extended interactional activity where the participants collectively worked to develop a new understanding of an interactional practice: a response particle that was not understood in the service encounter. The actions through which the participants clarify its meaning, practice the form and orient to the interactional import of the response during the co-constructed telling sustain orientation to a learning project driven by the trouble experienced, but not made explicit, during the service encounter. According to Levinson (2013:122), a project in interaction is not a sequence but a "plan of action" that at least one of the participants is pursuing. This resonates well with John's story: the practices of reenactment serve to build up and embellish the climax of the story. However, at the same time they work in the service of the learning project by establishing the clerk's response as the focus of shared attention and interest. It can be argued that John and Mark's joint project is to find out what the clerk's response meant, to comprehend why such a practice of responding was used, and to learn how a similar practice could be used in future interactions.

Practices of reenactment are an essential part of interactional competence in storytelling (see e.g. Goodwin 2007). The analysis shows how the events experienced are not just reported, but embellished and dramatized to make the story interesting for the recipients. John, who is the primary teller, succeeds in telling the complex story with limited linguistic resources: in spite of observable trouble with constructing verbal utterances, he is able to hold the floor and reenact the past event in a rather precise, nuanced and recipient-designed way. John's ability to depict the events and construct an entertaining performance of the identities and stances relies on multiple resources, including skilled use of embodied practices. Previous studies have highlighted how storytelling offers also students with low proficiency opportunities to participate and engage in interpersonal relationship work, which enables them to contribute to building a learning community (e.g. Hellermann 2008, Barraja-Rohan 2015). While earlier studies have largely focused on competences at the verbal level, this study demonstrates how multimodal resources contribute to the narrative performance and the way the group activity is transformed into an occasion for learning. This testifies to the richness of storytelling as an environment for creative L2 use and relational work. 
Both the service encounter and the group discussion analysed here were part of a pedagogical task that was designed for the learners (see Hellermann \& Pekarek Doehler 2010). Although the teacher set the task and gave general instructions for the small group discussions in the classroom, the students were free to plan and organize their activities in their own way. The analysis highlights how the focal participants, John and Mark, managed to accomplish the task creatively. In addition to conducting the business of buying coffee, John chose to ask a question that departed from the structural routine of service encounters. The data show in an intriguing way how the question, a possible preinvitation, was managed locally through multiple resources within the social and material ecology of the encounter. Even if the question was part of a larger pedagogic activity, it is clear that neither John nor Mark were prepared for the way the turn would be interpreted and responded to in the encounter. The way the situation unfolds makes visible the complexity and unpredictability of interactions outside the classroom. It is these qualities of interactions in the wild that make them challenging, memorable and tellable (Ortega 2015: 367) for participants. In this case the need to understand the clerk's response became the driving force behind the learning project in the retrospective discussion.

The videos recorded on the students' devices turned out to be a crucial resource in the learning project. Without the videorecording, it would not have been possible for the participants to orient to remembering, understanding and learning the target practice in such a detailed way. The smart phone enabled repeated listening, which was needed in order to first identify the form of the clerk's response, then clarify its meaning, and finally to figure out how the sequence continued. Our analysis therefore suggests that a smart phone can be a useful device in connecting language use experiences outside the classroom with discussions in the classroom. Another point worth noting is that the instructions guiding the retrospective discussions were not very specific (see App. 2): apart from a few openly framed questions, the students were free to discuss any aspect of the situations. This made it possible to observe how students themselves made sense of their experiences and how they identified objects of learning. Not all groups that participated in the project worked to analyse their interactions in as much detail as the group described here. However, the analysis illustrates how an experientially based task enabled these participants to initiate and sustain a project of investigating an object of learning and to display a new understanding of it.

Overall the data suggest that pedagogic activities that enable studentgenerated analysis and reflection of their own experiences of language use are meaningful and beneficial for L2 learning. The different phases of the three-part pedagogical task afford opportunities for attending to, rehearsing and using selected linguistic and interactional practices. The analysis demonstrates that the participants' focus is not just on the linguistic item, but rather on the way that it was used in its sequential and interactional context. The students analyse the focal practice in a much more detailed way than they were asked to in the instructions. One of the reasons for this is that the target practice was meaningful and potentially consequential for the students beyond the language learning task. In fact, John and Mark report in the classroom discussion that they went back to the clerk to ask whether her answer to John's question/pre-invitation was yes 
or no. Even though it has not been possible to trace the same participants beyond this occasion, it is safe to assume that an experience such as this is memorable and could influence possible future interactions between the participants. The consequentiality of the object of learning is also visible in the classroom discussion: the problem of understanding that did not surface in the out-of-classroom encounter is the driving force of the learning project. Further, the way the experience is reenacted reveals the participants' sensitivity to the complex interactional concerns at play. The reenactment is carefully co-constructed to highlight the humorous and entertaining facets of the experience while addressing the issues of non-understanding and competence.

The analysis shows in detail how the experiences in everyday language use situations can be "harvested and reflected upon" (see Wagner 2015: 77). The study thus contributes to current understanding of the reflexive relationship between the classroom and the students' lifeworld. Experiential language teaching pedagogies emphasize the importance of the learner's own experiences as the "fuel" for learning and the reflective practices that organize and give meaning to the experiences in relation to learning (see e.g. Knutson 2003). The case analysed here was clearly tellable and also particularly entertaining for the students to analyse. Not all the cases in our data exhibit such creative and humorous manifestations of the task. However, in all cases the restrospective telling of the participants' experiences furnishes the activity environment within which the participants identify and work with objects of learning. Experientially-based activities also enforce students' agency since the students are the primary "owners" of their own experiences: they are the only ones who know what really happened and how they felt during the interactions in the wild, and after. Our data shows that this expertise shapes the way the telling and also the learning activity are organised.

Finally, for the study of second language learning in interaction, the combination of data from the same participants interacting inside and outside the classroom is valuable. Even though interactions 'in the wild' are an important locus of study in their own right, discussions about the same interactions back in the classroom open up new possibilities for analyzing language learning as a social process. The retrospective classroom interactions show what the participants themselves treat as worth telling and learning, how they represent their experiences and address issues related to language use. They also enable detailed analysis of the practices through which targets of learning are located and analysed by the participants, i.e. how they orient to L2 learning as a social and collaborative activity.

\section{References:}

Barraja-Rohan, A.M. 2011. 'Using conversation analysis in the second language classroom to teach interactional competence,' Language Teaching Research 15/4: 479-507.

Barraja-Rohan, A. M. 2015. "“I told you”: Storytelling development of a Japanese learning English as a second language' in T. Cadierno and S. W. Eskilden (eds.): Usage-Based Perspectives on Second Language Learning. Mouton de Gruyter, pp. 271-304. 
Berger, E. and S. Pekarek Doehler. 2015. 'Direct reported speech in storytellings: Enacting and negotiating epistemic entitlements,' Text and talk 35/6: 789-813. doi: 10.1515/text-2015-0023

Clark, B. and K. Lindemalm. 2011. Språkskap. Swedish as a Social Language. Folkuniversitetet \& Interactive Institute.

Clift, R. and E. Holt. 2007. 'Introduction' in E. Holt and R. Clift (eds.): Reporting talk. Reported speech in interaction. Cambridge University Press, pp. 1-15.

Couper-Kuhlen, E. 2007. 'Assessing and accounting' in E. Holt and R. Clift (eds.): Reporting talk. Reported speech in interaction. Cambridge University Press, pp. 81-119.

Eskildsen, S. W. and G. Theodorsdottir. 2015. 'Constructing L2 learning spaces: Ways to achieve learning inside and outside the classroom,' Applied Linguistics. doi: 10.1093/applin/amv010

Eskildsen, S. W. and J. Wagner. 2013. 'Recurring and shared gestures in the L2 classroom: Resources for teaching and learning,' European Journal of Applied Linguistics 1/1: 139-161. doi: 10.1515/eujal-2013-0007

Eskildsen, S. W. and J. Wagner. 2015. 'Embodied L2 construction learning,' Language Learning 65/2: 419-448. doi: 10.1111/lang.12106

Gardner, R. and J. Wagner. 2004. Second Language Conversations. Continuum.

Goodwin, C. 1984. 'Notes on Story Structure and the Organization of Participation' in M. Atkinson and J. Heritage (eds.): Structures of Social Action. Cambridge University Press, pp. 225-46.

Goodwin, C. 2007. 'Participation, Stance, and Affect in the Organization of Activities,' Discourse and Society, 18/1: 53-73.

Greer, T. 2013. 'Word search sequences in bilingual interaction: Codeswitching and embodied orientation toward shifting participant constellations,' Journal of Pragmatics 57: 100-117.

Hall, J-K, J. Hellermann and S. Pekarek Doehler. 2011. L2 Interactional Competence and Development. Multilingual Matters.

Hellermann, J. 2008. Social Actions for Classroom Language Learning. Multilingual Matters.

Hellermann, J. and S. Pekarek Doehler. 2010. 'On the contingent nature of language learning tasks,' Classroom Discourse 1/1: 25-45. doi: 10.1080/19463011003750657

Heritage, J. 1984. 'A Change of State Token and Aspects of Its Sequential Placement' in J. Maxwell Atkinson and John Heritage (eds), Structures of Social Action, Cambridge, Cambridge University Press, pp. 299-345

Holt, E. 1996. 'Reporting on talk: The use of direct reported speech in conversation,' Research on Language and Social Interaction 29: 219-245.

Holt, E. 2007. “I'm envying your chop up mind': Reporting and enacting' in E. Holt and R. Clift (eds.): Reporting talk. Reported speech in interaction. Cambridge University Press, pp. 47-80. 
Hutchins, E. 1995. Cognition in the Wild. Cambridge: The MIT Press.

Jefferson, G. 1987. ‘On exposed and embedded correction in conversation' in G. Button and J. R. E. Lee (eds.): Talk and Social Organization. Multilingual Matters, pp. 86-100.

Kasper, G. and R. Burch. 2016. 'Focus on form in the wild' in R. A. van Compernolle and J. McGregor (eds.) Authenticity, Language, and Interaction in Second Language Contexts. Multilingual Matters, pp. 198-232.

Kasper, G. and M.T. Prior. 2015. 'Analyzing story telling in TESOL interview research,' TESOL Quarterly 49/2, 226-255. doi: 10.1002/tesq.169

Kasper, G. and J. Wagner. 2011. 'Conversation analysis as an approach to second language acquisition' in D. Atkinson (ed.): Alternative Approaches to Second Language Acquisition. Routledge, $117-142$

Kasper, G. and S. Kim 2015. 'Conversation-for-learning: institutional talk beyond the classroom' in Markee, N. (ed.): The Handbook of Classroom Discourse and Interaction. John Wiley \& Sons, 390408. DOI: 10.1002/9781405198431.wbeal0208

Knutson, S. 2003. 'Experiential learning in second-language classrooms,' TESL Canada Journal 20/2: $55-64$.

Koivisto, A. 2015. 'Displaying now-understanding: The Finnish change-of-state token aa,' Discourse Processes 52/2: 111-148. doi: 10.1080/0163853X.2014.914357

Koschman, T. 2013. 'Conversation analysis and learning in interaction' in Chapelle, C. A. (ed.): The Encyclopedia of Applied Linguistics. Blackwell.

Kramsch, C. 2000. ,' Second language acquisition, applied linguistics, and the teaching of foreign languages,' The Modern Language Journal 84: 311-326.

Kurhila, S. 2006. Second Language Interaction. John Benjamins.

Lantolf, J. and S. Thorne 2006. Sociocultural Theory and The Genesis of Second Language Development. Oxford University Press.

Lee, Y. 2010. 'Learning in the contingency of talk-in-interaction,' Text and Talk 30/4: 403-422. doi: $10.1515 /$ text.2010.020

Lee, Y.-A. and J. Hellermann. 2014. 'Tracing developmental changes through conversation analysis: Cross-sectional and longitudinal analysis,' TESOL Quarterly 48/4: 763-788. doi:10.1002/tesq.149

Lerner, G. 1992. 'Assisted storytelling: Deploying shared knowledge as a practical matter,' Qualitative Sociology 15/3: 247-271. doi: 10.1007/BF00990328

Levinson, S. C. 2013. 'Action formation and ascription' in T. Stivers and J. Sidnell (eds.): The Handbook of Conversation Analysis. Wiley-Blackwell, pp. 103-130. 
Lilja, N. 2014. 'Partial repetitions as other-initiations of repair in second language talk: Reestablishing understanding and doing learning,' Journal of Pragmatics 71: 98-116. doi:

10.1016/j.pragma.2014.07.011

Majlesi, A. R. and M. Broth. 2012. 'Emergent learnables in second language classroom interaction,' Learning, Culture and Social Interaction 1/3-4: 193-207. doi: 10.1016/j.lcsi.2012.08.004

Majlesi, A. R. 2014. 'Finger dialogue: The embodied accomplishment of learnables in instructing grammar on a worksheet,' Journal of Pragmatics 64: 35-51. doi: 10.1016/j.pragma.2014.01.003

Margutti, C. 2007. 'Two uses of third-person references in family gatherings displaying family ties: Teasing and clarifications,' Discourse Studies 9/5: 623-651. doi: 10.1177/1461445607082578

Markee, N. 2008. 'Toward a learning behaviour tracking methodology for CA-for-SLA,' Applied Linguistics 29/3: 404-427. doi: 10.1093/applin/amm052

Markee, N. and M.-S. Seo 2009. 'Learning talk analysis,' International Review of Applied Linguistics 47/1: 37-63.

Mondada, L. 2007.' Multimodal resources for turn-taking: Pointing and the emergence of possible next speakers,' Discourse Studies 9 /2: 195-226.

Mondada, L. 2014a. 'The local constitution of multimodal resources for social interaction,' Journal of Pragmatics 65: 137-156. doi: 10.1016/j.pragma.2014.04.004

Mondada, L. 2014b. Conventions for multimodal transcription. Available at: https://franz.unibas.ch/fileadmin/franz/user upload/redaktion/Mondada conv multimodality.pdf

Nguyen, H. t. 2012a. 'Social interaction and competence development: Learning the sequential organization of a communicative practice,' Learning, Culture and Social Interaction 1/2: 127-142. doi: 10.1016/j.lcsi.2012.05.006

Nguyen, H. t. 2012b. Developing Interactional Competence: A Conversation-Analytic Study of Patient Consultations in Pharmacy. Palgrave-Macmillan.

Norton, B. 2000. Identity and language learning. Gender, ethnicity and educational change. Pearson Education.

Ortega, L. 2015. 'Usage-based SLA: A research habitus whose time has come' in T. Cadierno and S. W. Eskilden (eds.): Usage-Based Perspectives on Second Language Learning. Mouton de Gruyter, pp. 353373.

Pavlenko, A. and J. Lantolf 2000. 'Second language learning as participation and the (re)construction of selves' in J. Lantolf (ed.): Sociocultural Theory and Second Language Learning. Oxford University Press, pp. 155-77.

Pekarek Doehler, S. 2010. 'Conceptual changes and methodological challenges: On language and learning from a conversation analytic perspective on SLA' in P. Seedhouse, S. Walsh, and C. Jenks (eds.): Conceptualising Learning in Applied Linguistics. Palgrave, pp. 105-126. 
Prior, M. 2015. 'Introduction: Represented talk across activities and languages,' Text and Talk 35/6: 695-705. doi 10.1515/text-2015-0026

Schegloff, E. 2007. Sequence organization in interaction. Cambridge: Cambridge University Press.

Sidnell, J. 2006. 'Coordinating gesture, talk, and gaze in reenactments,' Research on Language and Social Interaction 39/4: 377-409. doi: 10.1207/s15327973rlsi3904_2

Stivers, T. 2008. 'Stance, alignment, and affiliation during storytelling: When nodding is a token of affiliation,' Research on Language \& Social Interaction 41/1: 31-57. doi: 10.1080/08351810701691123

Stivers, T. 2011. 'Morality and question design: 'Of course' as contesting a presupposition of askability' in T. Stivers, L. Mondada \& J. Steensig (eds.): The Morality of Knowledge in Conversation. Cambridge University Press, pp. 82-106.

Stivers, T., L. Mondada and J. Steensig. 2011. 'Knowledge, morality and affiliation in social interaction' in T. Stivers, L. Mondada \& J. Steensig (eds.): The Morality of Knowledge in Interaction. Cambridge University Press, pp. 3-24.

Thompson, S. A., B. A. Fox and E. Couper-Kuhlen. 2015. Grammar in Everyday Talk: Building Responsive Actions. Cambridge University Press.

Thorne, S. 2013. 'Language learning, ecological validity and innovation under conditions of Superdiversity,' Balterra Learning and Teaching Language and Literature 6/2: 1-27.

Wagner, J. 2015. 'Designing for language learning in the wild: Creating social infrastructures for second language learning' in T. Cadierno and S. W. Eskildsen (eds.): Usage-Based Perspectives on Second Language Learning. Mouton de Gruyter, pp. 75-102.

Wilkinson, S. and C. Kitzinger. 2006. 'Surprise as an interactional achievement: reaction tokens in conversation,' Social Psychology Quarterly 69/2: 150-182. doi: 10.1177/019027250606900203

Wong, J. 2015 ‘Interactional know-how in storytelling: A look at L1-L2 phone conversation,' Paper presented at the IIEMCA conference 2015. Living in the material world. Kolding, Denmark. 4. 7.8.2015. 